\title{
ATHENS WATERFRONT DEVELOPMENT: THE PUBLIC SPACE AS A MEANS FOR SUSTAINABLE REGENERATION
}

\author{
ELENI SPANOGIANNI \& YIOTA THEODORA \\ Department of Urban and Regional Planning, School of Architecture, N.T.U.A., Greece
}

\begin{abstract}
Waterfront management is a crucial issue in spatial planning of coastal and port cities, with interest in it intensifying. In the current critical time of a multifaceted crisis in Greece - a country with a strongly coastal/insular-based character - the challenge of a comprehensive confrontation of this subject becomes even stronger, mainly due to climate change and local identity. Recognizing that this special category of space is characterized by complexity, the article seeks to contribute to the ongoing debate, emphasizing the need to change the way we face waterfront development and utilize its dynamics. The purpose of this research is the designation of a multidimensional methodological approach which seeks to investigate the capability of public space to assume a role as a unifying element for the reassurance of the city-sea relationship. The Athenian coastal zone is defined as a pilot field of investigation, focusing from the Faliron Bay to the Hellinikon area. The article states its interest on this highly urbanized area, where a concentration of hyper-local infrastructures and functions is confirmed. The objective is to investigate the question as to whether the public space can act as a means for the reinforcement of the urban coastal front, the assurance of its spatial continuity and its attribution to citizens' everyday life. It aims at re-opening the discussion through supporting the need for the creation of a coastal sustainable strategy integrated into an overall urban policy with emphasis on new structures of governance and the reassurance of the city-sea relationship with the public space acting as a catalyst. In this rationale, attention is given, inter alia, to the systematic study of the proposed planning practices referring to the pilot area, mapping its spatio-functional transformations as well as structuring a new indicator-based assessment system ready to contribute to the evaluation and measurement of possible future changes and dynamics.

Keywords: coastal/port cities, waterfront development, spatial policies and urban regeneration, spatial and environmental planning, livable cities and smart sustainability, public space, climate change and resilience.
\end{abstract}

\section{INTRODUCTION}

The management of the natural environment is a subject of special criticality in terms of spatial development and design. Especially during the last 15 years, where in conditions of climate change and search of new forms of smart development in terms of sustainability, resilience and competitiveness, the protection and exploitation of the elements of nature remain firmly at the center of scientific research. An objective that especially in coastal and port cities acquires unique interest due to the coexistence of multiple (often incompatible) uses. In these fragile loci, where the pressures in the natural and structured environment are intense, the recovery of urban coastal front and the assurance of the city-water connection are emerging as major planning challenges [1], [2]. A trend, that raises a number of issues related to the management of the coastal area and its organic integration into the urban fabric. In the process of retrieving the coastal front, public space is projected as the key. The question, thus, arises: whether, and under what conditions, spatial planning could contribute to the optimal utilization of public space as a developmental factor in general, but also as a unifying element in the scale of the city. The article seeks to contribute to this question through the investigation of: whether and under what conditions the development 
options/planning practices could contribute to the constitution of a livable urban coastal front, ready to function as an organic part of the city. An issue, which has not ceased to concern at the level of official state policies, but also at the scientific level [3], [4], returns dynamically to the current situation of the recent pandemic and in fact in conditions of a multifaceted crisis. The data is constantly changing, clearly highlighting new needs and priorities. This fact makes the reconsideration of the research and planning methodology of the coastal urban front more necessary than ever. The interest focuses on Greece at a time, when efforts are underway towards the modernization and strengthening of the country's position at the international scene through the determination of new forms and dynamics of the coastal space, as well. To this direction, the need for the redefinition of the planning of public space is projected more and more based on protection, resilience, security and health, as well as social justice. More specifically, the research which is presented at this stage (i.e. from the Faliron Bay to Hellinikon area) [5] is part of a broader investigation having as a place of reference the entire coastal urban area of the Metropolitan Region of Athens [6].

The article is organized into three thematic sections (Sections 2, 3 and 4) in an inseparable correlation among them (Fig. 1). The first section opens the topic through the presentation of public space as a means for urban regeneration. The second one (with a more practical character) highlights issues which have been arisen through the pilot research, while the third one (associating the general problematic with the findings from Athens) proceeds to the formulation of thoughts/suggestions that could help in the formation of an overall policy for urban coastal areas. Emphasis is placed on the importance of organizing new governance structures and on the optimal utilization of natural and cultural heritage [5]-[9].

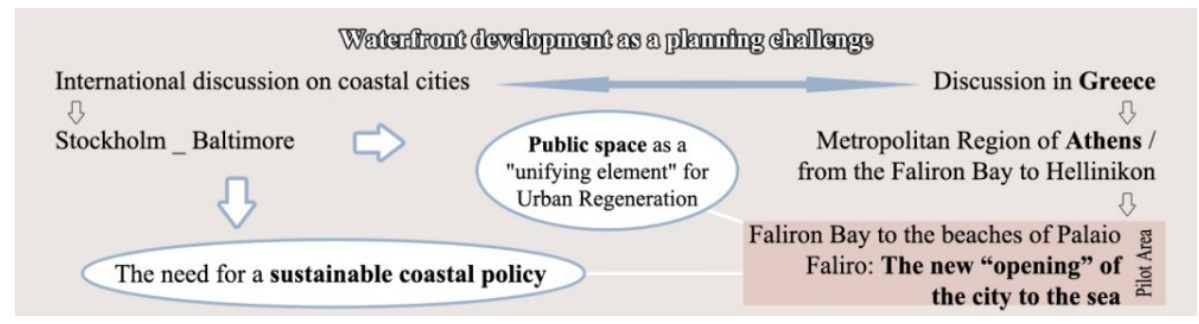

Figure 1: Basic thematic sections of research. (Source: Own processing.)

\subsection{The methodological approach}

The complexity of the coastal area poses particular difficulties that emphasize the need for special planning and therefore for the existence of an appropriate flexible methodology of research, assessment, imaging and ongoing surveillance. Contemporary experience and practice have highlighted on the one hand the importance of simultaneous observation of the urban coastal front as an organic part of the city, and on the other hand on the basis of monitoring the individual spatial parts, that make it up, and its interconnections with other areas of the city and beyond [2], [4]. In this rationale, the current debate about waterfront development and its importance in coastal cities' competitiveness and quality are being presented through the relevant literature. At the same time, in Greece the following are being investigated: (a) the current institutional framework for the coastal area and the environmental and spatial planning (e.g. implemented and proposed plans for the study area and more broadly, development policies, investment policy, etc.) and (b) the participants (key actors) in the planning process and their role. It is in the field wherea systematic recording, 
grouping and typing of the individual areas of the examined area is attempted based on specific environmental, spatial, and socio-economic criteria. Indicatively, crucial issues are approached which are related namely to the: (a) administrative structure, b) conditions of access and networking, (c) coastline features (landscapes/seascapes), (d) existence/quality of natural and cultural elements, (e) land uses and infrastructures, and (f) socio-economic characteristics of the Municipalities to which the investigated coastal areas belong. The main aim is: (a) the comprehension of the current situation and its dynamic development over time (1940-present), and (b) the identification of the implications of developmental and planning choices (or of their absence) on the natural and structured environment. The observation of the spatial-functional transformations and their effects takes place in important time-lapse sections, starting in 1940 and focusing on the last 20 years. During this period of 80 years, emphasis is placed on the designation of the factors that have functioned supportively or deterrently for the spatial continuity of Athens coastal front and the reassurance of its organic integration into the city. The main methodological tool for the observation and the evaluation was the processing of the aerial photographs of the area in the time periods/stations: 1940, 1962 and 1988 (Fig. 2). The cartographic depiction was followed by its correlation with quantitative and qualitative data, in order to draw conclusions about the character of the area and the role of the public space in it and beyond. In this regard, the interest has been focused on cartographic backgrounds and aerial photographs at various scales of 2019, in order to construct an overall database for the study area (i.e. Subsection A: the Faliron Bay: Municipalities of Moshato - Tavros, Kallithea and Palaio Faliro) (Figs 3 and 4).This area is, in the next phase, divided into four spatial subsections due to the differences among them regarding the: (a) existing conditions of access and networking and (b) features and elements of the route concerning nature and culture, the activities and infrastructure developed along the urban coastal front (or expected to develop), the quality of public space, the relationship with water as well as experiential actions to mention some. These differences make the distinction of the investigated area necessary for its optimal observation and the evaluation of the interconnections and correlations between its spatial parts (Fig. 4). At the same time, they constitute the criteria from which quantitative/qualitative indicators can emerge of spatial character (such as: geomorphology, structured-unstructured relationship, land uses, accessibility-networking), but also of socio-economic character (e.g. demographics, population density, etc.). Their determination is the subject of a following phase. The correlation and utilization of the cartographic material and the data from the field research in the present phase focus on the investigation of the existence of public spaces on the coastal front and the assessment of their quality and their spatial continuity (Figs 5 and 6).

\subsection{The Faliron Bay as a place of reference}

In the context of the problematic for the development of the coastal urban front, in Greece, a country with a strongly coastal/insular-based character, there are still open issues of its development, management and planning, which cause various problems in practice. Greece is a unique case of research as the total length of its coastline exceeding $15,000 \mathrm{~km}$, ranking the country 11th in the world. Country's intense coastal/insular character raises issues of unique interest as far as the development, management and planning of its coastal and port cities [2], [9]. Main reasons, inter alia, the fragmentary legislation for the coastal area and the planning of urban areas combined with the involvement of many actors, without always clear responsibilities and the absence of a suitable coordinator [4], [5]. Athens is obviously an interesting case, as it is a highly populated coastal city with exceptional history and unique natural beauty where three important ports operate (Piraeus, Rafina, Lavrio). The coastal 
character of Athens brings out critical issues related to waterfront management and development, the relationship between the city and the sea, the spatial continuity of coastal areas and their organic integration into everyday life. Issues that, despite the important efforts made so far, remain unsolved. As mentioned above, special attention is given on the coastal zone from the Faliron Bay to the Hellenic Metropolitan Park. The specific area administratively belongs to five Municipalities (Moschato-Tavros, Kallithea, PalaioFaliron, Alimos and Hellinikon-Argyroupoli) (Fig. 3). It is an extremely dynamic coastal urban front characterized by: (a) a high concentration of infrastructures and functionsof supralocal importance, (b) intense densities, and (c) significant supra-local connections (i.e. road axes, transport systems). In this area dynamically organized spatial sections functioning as main sacs of tourist uses and recreation coexist with residential areas, as well as areas characterized by environmental degradation and quality problems. In such contradictory conditions, an intense investment interest dominates. Something which provokes various reactions, often tensions at the local community level. Indubitably the structure and the special features of Athens waterfront introduce management and development dilemmas. Hence, multiple planning challenges emerge at all different geographical levels [4], [8]-[9].

The special interest about Subsection A (the Faliron Bay: Municipalities of Moschato-Tavros, Kallithea and Palaio Faliro) was not random. This is an area defined by two natural boundaries of special importance for Athens, which are also administrative boundaries. Specifically, from the west the Kifissos river (its estuary is located inthe Faliron Bay) and from the east the Pikrodafni Stream (Fig. 4). The area, due to its special features and the intense interest, which gathers especially in the recent mainly 10 years, constitutes a key reference point and one of the most central exits of the city towards the sea. The already planned in progress large-scale interventions in the area of the Faliron Bay - related to city's "openness" to the sea - give to the specific area an additional (even stronger) dynamic. Its proposed distinction into four spatial subsections under the coastal road (Posidonos) raises a variety of issues in the exploration of typologies of public space and its qualities, through a logic of comparative view but also of a simultaneous approach of the wider space, where these areas belong to. More specifically the subsections are: (a) Subsection A1: part of the Faliron Bay/Municipality of Moshato-Tavros, (b) Subsection A2: part of the Faliron Bay/Municipality of Kallithea, (c) Subsection A3: Faliro Delta and Marina Floisvou/Municipality of Palaio Faliro, and (d) Subsection A4: Beaches of Palaio Faliro/Municipality of Palaio Faliro) (Fig. 4).

\section{THE PUBLIC SPACE AS A MEANS FOR URBAN REGENERATION}

In the context of globalization, spatial networking organization and climate change, coastal and port cities are gaining particular interest in the countries' development policies. The challenge and bet at the planning level are the organization of the public space in such a way, that it functions as a unifying element in the redefinition of the city-water relationship. An objective which especially in port cities presents additional interest, since the evolution of the production model and the changes in the organization and operation of modern ports require additional space, strengthening the tendency of their relocation away from the urban fabric - trend which allows the release of old port infrastructures. Thus, gaps arise, raising the issue of their reuse through their re-planning with the public space and the placement of tourism, leisure and culture facilities as the keys. Particularly in the case of port cities, the interest for urban coastal front is inextricably linked to the peculiarities of their economy, their strategic position, new technologies, but also to the incompatibilities found in the uses and the quality of the space at a local scale [2], [10]-[13]. In these fragile locales, the city-water relationship is redefined and projected as a comparative advantage. The main 
difficulty lies with the management of the plans that concern the port and those, that refer to the city. Thus, the recovery of the coastal front in port cities, as well as in coastal ones in general, is a dominant issue, as they are called upon to find the balance between global competitiveness and local sustainability and identity [13], [14]. In this rationale, where the public space is projected as a catalyst for the development and a means for the reconnection of the city with the water, its species and its typologies gain additional research interest. Of equal interest are parameters which, directly or indirectly, affect the use of the public space and the degree of appropriation, such as: (a) its ownership status, (b) who is (are) the actor(s) responsible for its management, and (c) who are the participants in the planning process (public and private sector, citizens). The above raise issues related to: whether and to what extent public spaces on the coast are "open" and under what conditions [2], [4], [7].Thus, the following are of major concern: (a) to whom public spaces are addressing to and what they offer, (b) how safe they are and to what extent they contribute to the quality of the urban environment [13], [15].

The international practice and experience have to show interesting examples implemented so far, through which the criticality of public space in the rebirth of coastal cities and port cities is projected, highlighting at the same time the importance of the active citizens' participation in their planning process, but also the criticality that the composition of the participants may have (public and private sector bodies, investors, citizens) [2], [4], [14]. Indicative reference is made for the case of Stockholm and Baltimore, two cities that have developed a particularly positive relationship with water through long-term strategic actions based on innovative governance structures and the establishment of cooperative relations with citizens [16]-[18]. In the case of Stockholm (Green Capital 2010) emphasis was placed on three axes: (a) the adaptation to climate change (e.g. technical infrastructure, water level, green, ecological materials, sustainable energy sources), (b) the reassurance of the accessibility and the sustainable urban mobility (unimpeded movement of pedestrians and bicycles, public transport, development of public spaces by the water, etc.) and (c) the defense of the complexity of uses and the location of infrastructure of supra-local importance. Equally interesting is the case of Baltimore, as is among the most successful examples of the renovation of former port facilities and their return to the city. The key is the establishment of public-private partnership through the creation of a single management and planning body (Baltimore Waterfront Development), as well as the development of actions for the public awareness on issues of protection and use of local identity. In both cases the public space is the key and the basic planning idea has to do with the reassurance of the spatial continuity and interconnection of its individual sections via routes with stop-motion networks along the water, while aiming at a connection with the historic areas of the cities and their neighborhoods.

Observing the international practice regarding the management of the coastal urban front, it appears that, regardless of the scale of the cities, common developmental and planning issues are emerging. Main principles of planned projects are, among others, the protection and management of history and natural and cultural heritage, the reassurance of access and sustainable mobility, the multifunctionality, the security and the formation of sustainable healthy public spaces. Experience has shown that the variety and spatial continuity of the activities in a public space constitute major principles for the formation of vibrant and creative waterfronts [10], [15], [19]. Parallel to the above, ensuring a variety of public spaces (i.e. scale, form, etc.), where security and image exchange are ensured, can play a crucial role in the pedestrian's choice to walk [20], [21]. Therefore, the variety of qualities and the spatial continuity of the coastal urban front enhance the development of experiential activities by the water and shape conditions of euphoria and creative search. 


\section{FALIRON BAY - ATHENS MEETS THE SEA}

The interest for the opening of the city to the sea is special in Athens. Various efforts have been made towards this direction. One of the most recent and much-discussed is the case of the Faliron Bay, which is part of the new narrative, which is formed in recent years for the coastal zone; that of the Athenian Riviera and the unified planning of the area, which raises new dilemmas and challenges. This area has at times starred in development visions of which little have been realized. In modern times, the vision of its exploitation and, by extension, of the opening of Athens towards the Saronic Sea front, comes to the fore again through areas of recreation, culture, sports and tourism, and more specifically, through the recent completion of the construction of the Stavros Niarchos Foundation Cultural Center, which is a catalyst project for the initiation of the procedures for the redefinition of the Athens' relationship with the coastal front. The aforementioned pursuit is a developmental practical application of the directions of the New Regulatory Plan of Athens-Attiki (Law 4277/2014), the text of which uses the choice of the subheading Athens - Mediterranean Coastal Metropolis in order to make its coastal area a key comparative advantage. Indicatively it is mentioned that the seafront axis of the city from the Faliron Bay to Vouliagmeni is defined as development axis of metropolitan radiation, among which the Metropolitan Pole of the Hellenic Agios Kosmas and the Pole of the Faliron Bay are defined as poles of international and national range.

In order to approach this "new" opening of the city to the sea, the reading of the area takes place at different spatial levels. Initially, the observation of the area is realised through a broader rationale of understanding the space (from the Faliron Bay to Hellinikon) through its transformations since 1940 (Section 3.1.) (Fig. 2) and then emphasis is given to the pilot area Subsection A (Fig 3), which is part of the wider area, in order to discover the public space, which exists under the road on a comparative basis (Section 3.2.). More specifically, the approach of its qualities, its differences and its spatial continuities and discontinuities takes place both along the coastline and in relation to the city, so that in the last section of this section some first interesting findings and some open questions emerge through all this interaction (Section 3.3.).

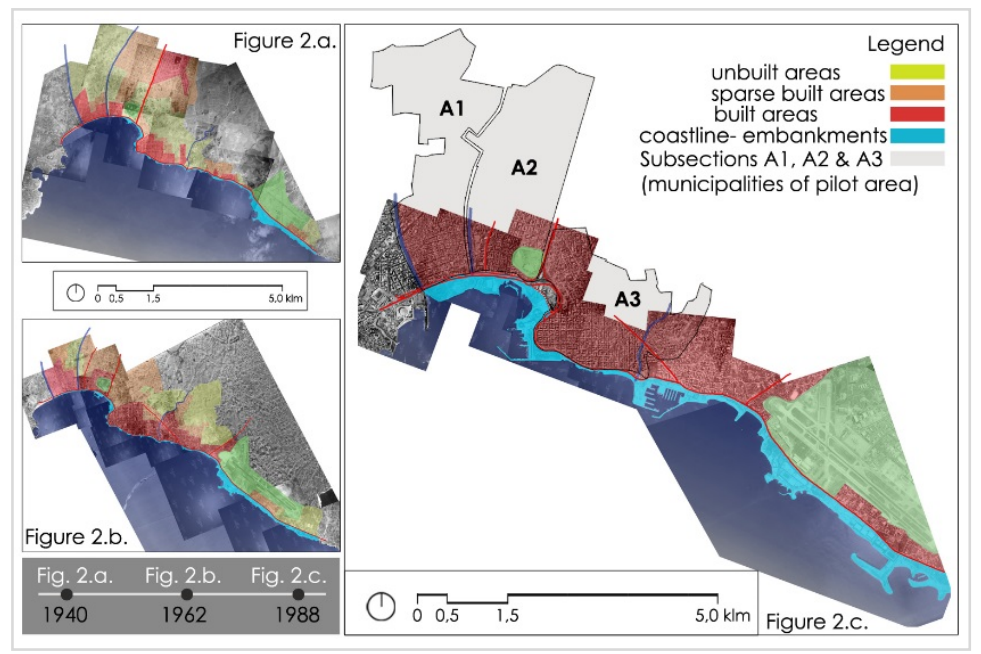

Figure 2: The Space-functional transformations of the broader area. (a) 1940; (b) 1962; and (c) 1988. (Source: Aerial photographs, own processing.) 
3.1 From the Faliron Bay to Hellinikon: Space-functional transformations and dynamics after 1940

The complexity of the area from the Faliron Bay to Hellinikon (Fig. 3) is of particular interest in terms of its spatial-functional transformations and its dynamics, which are considered worth approaching. At this stage, as shown in Fig. 2, the successive changes in the density of the urban fabric of the city are highlighted in parallel view with the successive changes in the geomorphology of the coastal front (due to embankments, marine constructions, etc.) and accessibility conditions (due to the construction of new infrastructure as well as transport projects).

More specifically, during the first post-war period, the capital kept a "distance" from the beach, while the urban front was formed in an inconsistent narrow strip, parallel to the coast, at a depth of a few building blocks (Fig. 2(a)). Then, the 1970s is considered a crucial decade for the coastal zone of the Saronic Gulf, because it was then, that a series of spatial interventions began, most importantly the large technical embankments (in the Faliron Bay, Marina Floisvou, Marina Alimou and Marina of Agios Kosmas in Hellinikon), while the process of urbanization, that had begun in the previous decade, expands within the urban fabric (Fig. 2(b) and (c)). Then, during the 1980s, road construction works began, mainly related to the creation of the elevated Poseidon Avenue in the area of the Faliron Bay, a time when the generalization and expansion of the use of private cars and the strengthening of the role of the Airport of Hellinikon as a transportation hub contributed to the beach gaining a different interest. It is also characteristic, that in the next decade the first uses of culture-sports-recreation will begin to be located in specific places along the entire length of the study area, with the result that the area will receive large tourist and commercial development cargoes, intention which eventually manifests in the following years.

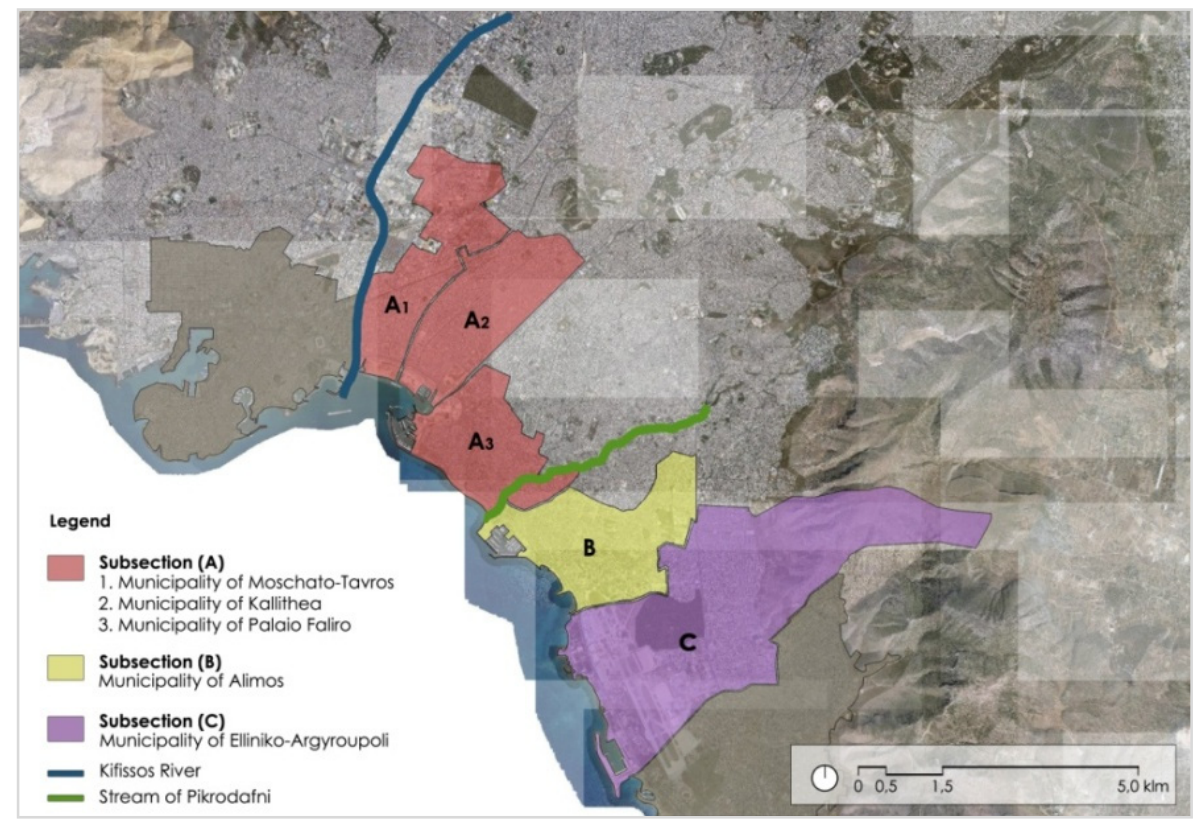

Figure 3: The geographic location of the coastline of the study area. (Source: Google Earth, own processing.) 
3.2 Investigating the different qualities of public space under the coastal road Posidonos

The place of reference Subsection A (Section 1.2.) presents a special complexity and diversity not only in terms of the existence or non-existence of spatial continuity between the four individual spatial units of the zone below the road, which compose it (Fig. 4), but also in terms of the relations, that develop, with the urban coastal front and consequently with the hinterland.

More specifically, for the investigation of the public space below the coastal road emphasis was given both on the cartographic material and on the quantitative approach of some indicators (as analyzed in Section 1.1.), concerning the: (1) total area ofeach subsection in 2019, (2) division of the total area of each subsection in the four basic categories (indoor buildings, outdoor facilities, open spaces and infrastructure) and (3) analytical approach of the category of open spaces in the current situation. Based on the above, the following table (Fig. 5) presenting these quantitative dimensions was created, which are of major interest for the approach of the public space at the present research effort. A first noteworthy remark is that all four areas (A1, A2, A3 and A4) are characterized by adequacy in open spaces, which show significant differences in their character and qualities. Open Spaces' division into natural landscaping, parks and routes for pedestrians and cyclists and unused areas gives a better picture of public space' quality of each subsection, resulting in some important findings. More specifically, with regard to Subsection 1, the - important for the city - free spaces within it remain unused in their entirety, a situation which is expected to be settled through the upcoming operations in the Faliron Bay. It is noted that these interventions also include Subsection 2, so they are expected to reverse the picture of the unused areas of this subsection as well, while in terms of the percentage occupied by open areas in the total area of each subsection, Subsections 1 and 3 present a corresponding image (54\% and $52 \%$, respectively).

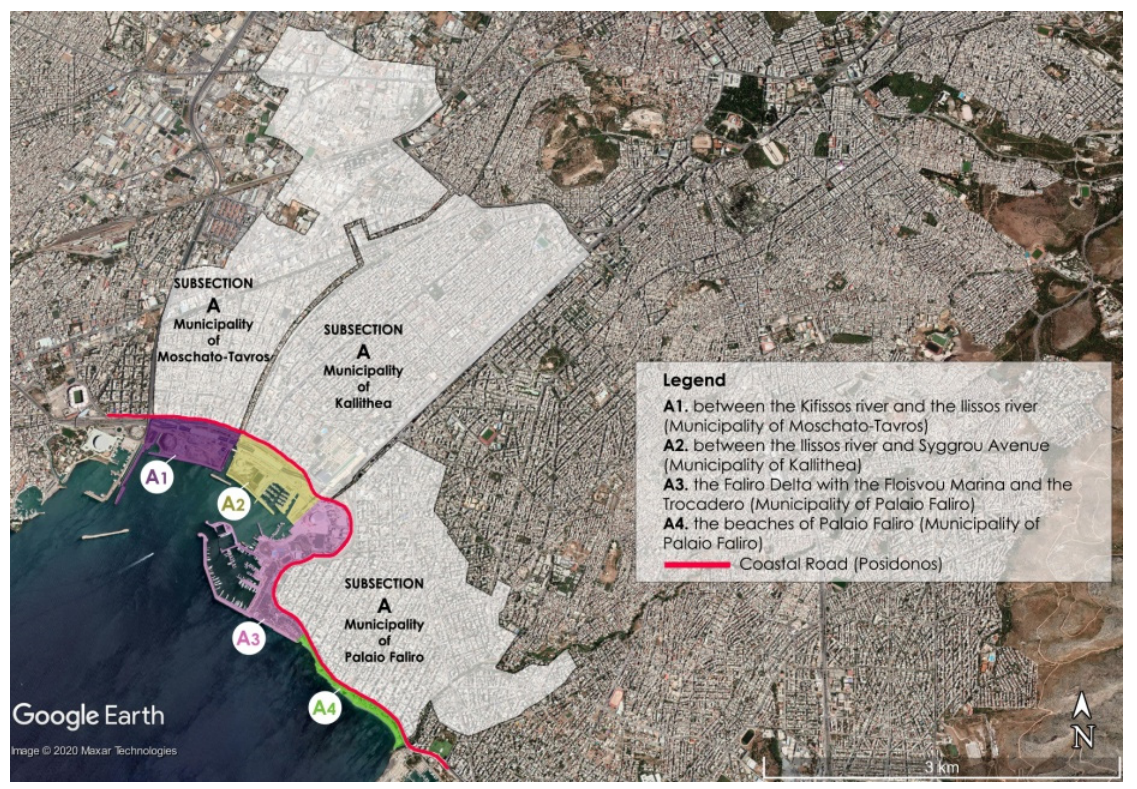

Figure 4: The distinction of the pilot area into four subsections under the coastal road. (Source: Google Earth, own processing.) 


\begin{tabular}{|c|c|c|c|c|c|}
\hline & & \multirow{2}{*}{$\begin{array}{c}\begin{array}{c}\text { Part of Faliron Bay } \\
\text { (Municipality of } \\
\text { Moschato-Tavros) }\end{array} \\
\text { Subsection } 1 \\
\end{array}$} & \multirow{2}{*}{$\begin{array}{c}\text { Part of Faliron Bay } \\
\text { (Municipality of } \\
\text { Kallithea) }\end{array}$} & \multirow{2}{*}{$\begin{array}{c}\begin{array}{c}\text { Faliro Delta \& } \\
\text { Marina Floisvou } \\
\text { (Municipality of } \\
\text { Palaio Faliro) }\end{array} \\
\text { Subsection } 3 \\
\end{array}$} & \multirow{2}{*}{$\begin{array}{c}\text { Beaches of Palaio } \\
\text { Faliro } \\
\text { (Municipality of } \\
\text { Palaio Faliro) }\end{array}$} \\
\hline & & & & & \\
\hline \multicolumn{2}{|c|}{ Total Area (sq.m) } & 327.340 & 329.050 & 517.800 & 85.360 \\
\hline \multirow{4}{*}{ 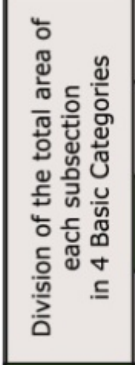 } & $\begin{array}{l}\text { Indoor } \\
\text { Buildings }\end{array}$ & $\begin{array}{c}0 \\
0,00 \% \\
\end{array}$ & $\begin{array}{l}18.800 \\
6,00 \% \\
\end{array}$ & $\begin{array}{l}33.710 \\
6,00 \%\end{array}$ & $\begin{array}{l}1.400 \\
2,00 \%\end{array}$ \\
\hline & $\begin{array}{l}\text { Outdoor } \\
\text { Facilities }\end{array}$ & $\begin{array}{c}0 \\
0,00 \%\end{array}$ & $\begin{array}{l}13.800 \\
4,00 \%\end{array}$ & $\begin{array}{c}50.790 \\
10,00 \%\end{array}$ & $\begin{array}{l}2.000 \\
2,00 \%\end{array}$ \\
\hline & Open Spaces & $\begin{array}{l}267.290 \\
82,00 \%\end{array}$ & $\begin{array}{l}176.650 \\
54,00 \%\end{array}$ & $\begin{array}{l}267.590 \\
52,00 \%\end{array}$ & $\begin{array}{c}67.060 \\
79,00 \%\end{array}$ \\
\hline & Infrastructure & $\begin{array}{r}60.050 \\
18,00 \%\end{array}$ & $\begin{array}{l}119.800 \\
36,00 \%\end{array}$ & $\begin{array}{l}165.710 \\
32,00 \%\end{array}$ & $\begin{array}{c}14.900 \\
17,00 \%\end{array}$ \\
\hline \multirow{3}{*}{ 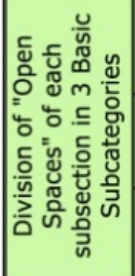 } & $\begin{array}{c}\text { Natural } \\
\text { Landscaping }\end{array}$ & $\begin{array}{c}0 \\
0,00 \%\end{array}$ & $\begin{array}{c}0 \\
0,00 \%\end{array}$ & $\begin{array}{c}0 \\
0,00 \%\end{array}$ & $\begin{array}{c}49.260 \\
73,00 \%\end{array}$ \\
\hline & $\begin{array}{c}\text { Parks / Routes } \\
\text { for pedestrians } \\
\text { \& cyclists } \\
\end{array}$ & $\begin{array}{c}0 \\
0,00 \%\end{array}$ & $\begin{array}{l}109.300 \\
62,00 \% \\
\end{array}$ & $\begin{array}{l}259.240 \\
97,00 \%\end{array}$ & $\begin{array}{r}17.800 \\
27,00 \%\end{array}$ \\
\hline & $\begin{array}{l}\text { Unused } \\
\text { Areas }\end{array}$ & $\begin{array}{r}267.290 \\
100,00 \%\end{array}$ & $\begin{array}{c}8.350 \\
38,00 \%\end{array}$ & $\begin{array}{c}517.800 \\
3,00 \%\end{array}$ & $\begin{array}{c}0 \\
0,00 \%\end{array}$ \\
\hline
\end{tabular}

Figure 5: Comparative approach for the 4 Subsections of the pilot area below the coastal road with quantitative criteria. (Source: Own processing.)

Regarding Subsection 3, the existence of parks and routes for pedestrians and cyclists is remarkable (97\% of its free spaces). A fact, which suggests that the social role of the public space functions and, also, highlights an attractive space for the citizens, with properly designed sections in terms of qualities of public space, and consequently a livable part of the city. Finally, with regard to Subsection 4, the fact that most of its area is dominated by natural landscaping ( $73 \%$ of its free space) is of particular interest, a remark that is very important for the protection of the natural coastline, which in the other three subsections - due to the construction of marinas and embankments - has been dramatically altered.

\subsection{Findings from the field research and open questions}

In order to approach the first findings, which emerge from the field research of the selected pilot area, it is advisable to combine the above quantitative approach with the qualitative approach, which was followed in a previous research stage for the whole study area (from the Faliron Bay to Hellinikon), so that the up to now field research can be enriched with the new quantitative data, correlated with them and re-examined. More specifically, through the double reading of the proposed grid diagram (vertically and horizontally) (Fig. 6), a first reading of the public space and its qualities has been made, while at the same time both the positive and negative elements of the individual spatial units and the correlations between them were highlighted, with the aim of identifying the spatial discontinuities, that interrupt a unified route by the water. 


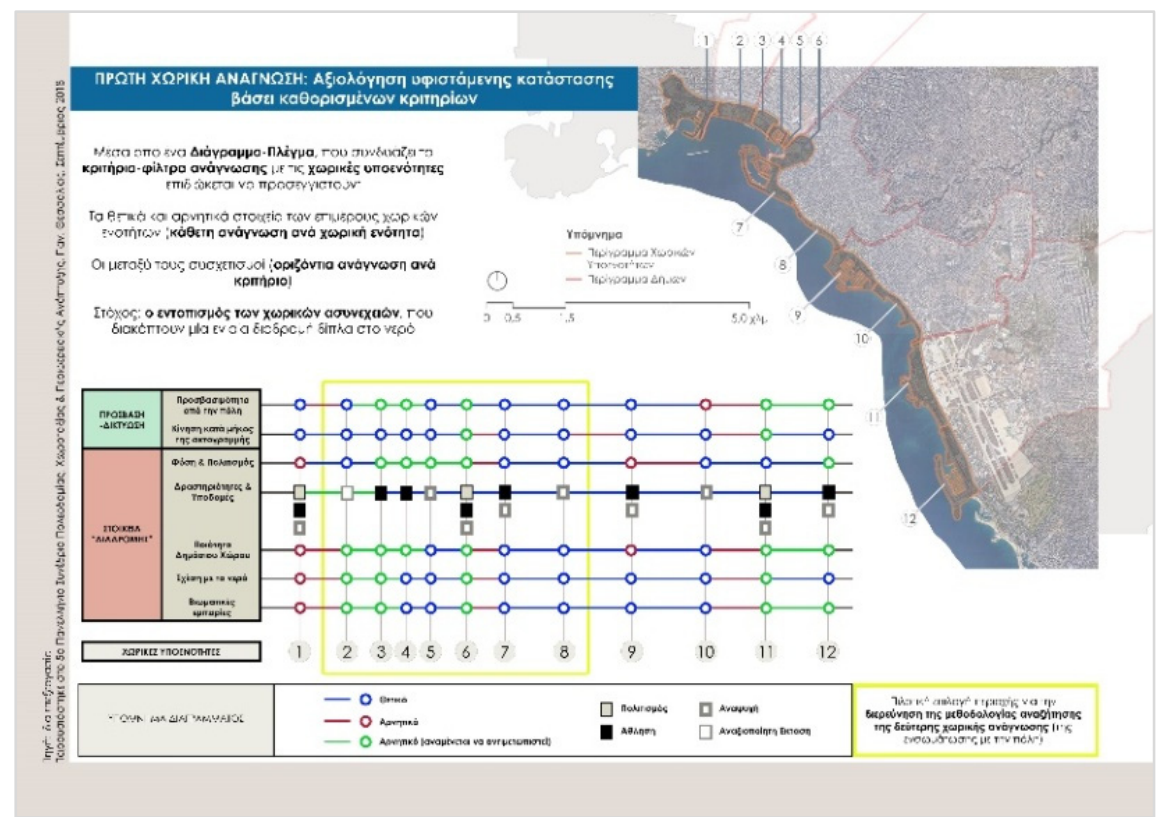

Figure 6: Qualitative approach of the pilot area with emphasis on the axes: (a) accessnetworking; and (b) land uses-activities. (Source: Own processing in Greek.)

More specifically, with regard to the first axis of access-networking, the operation of the coastal road as a barrier between the city and the coastal area along the largest part of the study area is considered particularly problematic. This picture is particularly strong in Subsection 1 (sub-area 2 of Fig. 6), while a similar picture appears in Subsection 2 (sub-areas 3, 4 and 5 of Fig. 6), where Esplanade is recognized as a positive design movement, which is an above-ground route of unification of the city, and specifically of the Stavros Niarchos Foundation Cultural Center (artificial point public space with a supra-local character above the coastal road) with the sea. Via the forthcoming interventions in the Faliron Bay these issues are expected to be solved, as the reassurance of the operational and physical continuity along the coastal zone is pursued, as well asthe strengthening of the city-sea relationship. Regarding Subsection 3 (sub-areas 6 and 7 of Fig. 6), although some obstacles are identified in the form of railings in the area of Faliro Delta and in its transitional zone of its connection with the spatial unit of Marina Floisvou - which arise due to ownership status - access from the city is considered satisfactory. Finally, in Subsection 4 (sub-area 8 of Fig. 6), the best access conditions to the coastal area are identified, as the flat pedestrian crossings allow the direct contact of the inhabitants with the water element, while in this part of the coastal zone the picture is also positive regarding on the unimpeded movement of pedestrians along the coastline.

At the level of land uses, those that are identified (tourism, commerce, culture, sports, education and recreation) appear to be compatible with the applicable legislation. It is noteworthy, that these uses are of interest in the present approach not so much regarding the ownership status of the land or building in which they are developed, but regarding the public access, as it is argued that issues that create spatial discontinuities due to the ownership status may be addressed through the arrangement and proper handling of uses. This desired spatial 
continuity seems to be broken by the existence of large unused areas and significant building stock in Subsection 1 (sub-area 2 of Fig. 6) in Faliron Bay, elements that, if used properly through the forthcoming interventions, can make a positive contribution to the confrontation of the lack of cohesion along the coastal front and have multiple benefits for the city. At this point it is advisable to formulate a concern about whether, and to what extents, more uses for the maritime space could be developed, so that this part of the coastal zone really functions as a privileged space between land and sea, an issue that can be approached at a later stage of research through a different methodology.

Closing the present section, it is noted that the proposed methodology for reading space through a quantitative and qualitative approach is part of a broader effort to formulate a methodological framework for the study area both to assess the current situation and to develop scenarios for the implementation of different policies. The aim of the research on the pilot area is not the simple aggregation of information but the apprehension of the complexity of the place of reference and the importance of the simultaneous display of spatial-functional data, the direct contact with the field and the designation of an innovative methodology of a multidisciplinary evaluation of the information. The further pursuit of this research effort is, via the identification of problems and the comparative advantages, to examine both the prospects of the exploitation of the study area and the optimal method of approaching an overall view of the urban coastal front of the Metropolitan Region of Athens.

\section{WATERFRONT DEVELOPMENT NEEDS A COMPREHENSIVE POLICY}

Through this route, multiple issues are highlighted for further investigation, both related to the management and planning of the special category of the urban coastal front and the emergence of public space as a catalyst for the reassurance of the city-sea relationship. In the international community, the ever-increasing interest of cities for the element of water is undeniable, seeking to highlight the conscious shift in its management as a means for changing the image of places. In this direction, the public space and the utilization of the local cultural heritage play a key role [22]. It is estimated that the public space is treated as a development factor for the image of the city; a finding that was approached briefly through the reference to the implemented design practices of international experience (Section 2). In Greece, although some important steps have been made to address the issues of interest, there are still some open issues. The aim of this effort is the contribution to the discussion through the communication of the first findings of a broader research, which having the Metropolitan Region of Athens as a spatial field of reference, investigates issues of accessibility, regulation of the individual spatial units of the urban coastal front and the relations between them, planning and implementation mechanisms, arrangement of land uses along the coastline, management of the natural and cultural environment, addressing impacts from climate change but also issues related to the management of natural disasters (such as the rise of the sea level) to name a few [4], [7], [8], [23].

It is argued that the reassurance of a successful development of the urban coastal front demands the creation of a coastal sustainable strategy integrated into an overall urban policy with the public space acting as a catalyst. The main challenge of planning at this level is the development of an organized network of public spaces on the urban coastal front by giving special emphasis to the following axes: (a) improvement of the accessibility from the city and special concern for the possibility of the existence of sustainable mobility along the coastline, (b) reconstruction of the land and sea divisions through a balanced development between economic pursuits and environmental parameters and c) functional and aesthetic upgrade of the coastal zone and reassurance of its vitality [2], [6]. At the same time, the observance of participatory procedures in the design process are considered to be of major 
importance, as well as the re-examination of new governance structures at the metropolitan level, which will be able to support the unified management of the coasts aiming at the better organization of the actions, the coordination of all stakeholders and the improvement of the effectiveness and monitoring of the application [4], [18], [24]. By highlighting the multiplicity and complexity of the relationships and interrelationships between them, this research effort leads to new research questions both about ways to manage and design the urban coastal front, as well as for the further search of the role of public space as a mechanism for strengthening the coastal front and ensuring its spatial continuity.

\section{REFERENCES}

[1] Gospodini, A., Urban waterfront redevelopment in Greek cities: a framework for redesigning space. Cities, 18(5), pp. 285-295, 2001.

[2] Theodora, Y., (ed.), Regional Unit of Piraeus, A Special Issue on Spatial Planning and Development, National Technical University of Athens, School of Architecture, Department of Urban \& Regional Planning: Athens, Greece, 2019. https://ntua.academia.edu/YiotaTheodora. Accessed on: 10 Jun. 2020.

[3] Daamen, T., Strategy as a Force: Towards Effective Strategies for Urban Development Projects: The Case of Rotterdam City Ports, IOS Press: Amsterdam, NL, 2010.

[4] Theodora, Y., The issue of teaching "spatial planning" - Thoughts on dealing with modern requirements and challenges of development of space. Maritime Space Urban Coastal Front - Port Cities, A Collection of Texts on Spatial Planning, ed. Y. Theodora, National Technical University of Athens, School of Architecture, Urban Planning Research Lab, Greece, 2018. www.arch.ntua.gr/publication/14430. Accessed on: 10 Jun. 2020.

[5] Spanogianni, E. \& Theodora, Y., Coastal space as a means for urban development. The case of Faliron Bay in Athens, Pre-Organized Special Session: Urban pressures in coastal and island areas: the challenges in implementation of maritime spatial planning in Greece. 3rd International Conference on Changing Cities III: Spatial, Design, Landscape \& Socioeconomic Dimension, pp. 526-535, 2017.

[6] Spanogianni, E. \& Theodora, Y., Space-functional transformations and developmental dynamics in the Seafront of Athens. The need for a sustainable coastal policy, 58th Congress of Ersa: Places for People: Innovative, Inclusive and Liveable Regions, August 28-31, Cork, Ireland, 2018.

[7] Theodora, Y., Land Uses as an Expression of the Developmental Model in Space. Issues of Methodological Consideration for Spatial Development and Regulation; A Collection of Papers. National Technical University of Athens, School of Architecture, Department of Urban \& Planning, Greece, 2014. (In Greek.)

[8] Spanogianni, E., \& Theodora, Y., Athens Waterfront planning a 'livable' public space by the sea. Proceedings of the 4th International Conference on "Changing Cities III: Spatial, Design, Landscape \& Socioeconomic Dimension”, Chania, Crete, Greece, pp. 294-305, 2019.

[9] Theodora, Y., Aegean Sea - Challenges and Dilemmas in Management and Planning for Local Development in Fragmented Insular Regions. Heritage, 2(3), pp. 1762-1784, 2019. https://doi.org/10.3390/heritage2030108.

[10] Galland, D. \& Hansen, C.J., The roles of planning in waterfront redevelopment: from plan-led and market-driven styles to hybrid planning? Planning Practice \& Research, 27(2), pp. 203-225, 2012. 
[11] Hein, C., Port cities and urban wealth: between global networks and local transformations. International Journal of Global Environmental Issues, 13(2/3/4), pp. 339-361, 2014.

[12] Girard, L.F., Kourtit, K. \& Nijkamp, P., Waterfront areas as hotspots of sustainable and creative development of cities. Sustainability, 6, pp. 4580-4586, 2014.

[13] Theodora, Y., Paving Smart and Sustainable Pathways for Port cities in a Challenging Era - Open Issues of Development and Planning, 4th Euro-Mediterranean Conference on VISIONING MED 2020+/Mediterranean in Transition: Preserving the Past Preparing for the Future, Athens, 9-10 Oct. 2020.

[14] Jessop, B., Liberalism, Neoliberalism and urban governance: A state-theoretical perspective. Antipode, 34(3), pp. 452-472, 2002.

[15] Carr, S., Francis, M., Rivlin, L.G. \& Stone, A.M., Public space, Cambridge University Press: Cambridge, 1992.

[16] Bassett, K., Griffiths, R. \& Smith, I., Testing governance: partnerships, planning and conflict in waterfront regeneration. Urban Studies, 39(10), pp. 1757-1775, 2002.

[17] City of Stockholm, Homepage. https://international.stockholm.se. Accessed on: 17 Jul. 2020.

[18] Waterfront Partnership of Baltimore, Homepage. www.waterfrontpartnership.org/. Accessed on: 17 Jul. 2020.

[19] Jacobs, J., The Death and Life of Great American Cities, Vintage: New York, 1961.

[20] Handy, S., Urban form and pedestrian choices: Study of Austin neighborhoods, Transportation Research Record, 1552, Transportation Research Board, Washington, D.C., 1996.

[21] Jaskiewicz, F., Pedestrian level of service based on trip quality, Transportation Research Board Circular E-C019: Urban Street Symp., Transportation Research Board, Washington, D.C., 2001.

[22] Theodora, Y., Cultural Heritage as a means for Local Development in Mediterranean historic cities - The need for an Urban Policy. Heritage, 3(2) pp. 152-175, 2020. https://doi.org/10.3390/heritage3020010.

[23] Theodora, Y., Natural hazards: key concerns for setting up an effective disaster management plan in Greece. Euro-Mediterranean Journal for Environmental Integration, 5, pp. 38, 2020. https://doi.org/10.1007/s41207-020-00174-y

[24] Theodora, Y., Democracy in Planning. Why Education Matters? (Seminar on World City Planning Day). Spatial Planning and Local Democracy. Association of Greek City and Regional Planners, School of Architecture, National Technical University of Athens, Athens, 2016. (In Greek.) 